\title{
Comparison of patient comfort between iodixanol and iopamidol in contrast-enhanced computed tomography of the abdomen and pelvis: a randomized trial
}

Acta Radiologica

2014, Vol. 55(6) 7I5-724

(C) The Foundation Acta Radiologica 2013

Reprints and permissions: sagepub.co.uk/journalsPermissions.nav DOI: $10.1|77 / 0284| 851 \mid 3505277$ acr.sagepub.com

๑SAGE

\author{
Frederick L Weiland', Luis Marti-Bonmati ${ }^{2}$, Lauren Lim $^{3}$ and \\ Hans-Christoph Becker ${ }^{4}$
}

\begin{abstract}
Background: Previous clinical studies have shown that iso-osmolar iodixanol (Visipaque ${ }^{\circledR}$ ) causes less patient discomfort than low-osmolar contrast media (LOCM) when administered via intra-arterial injection. No data are available comparing these agents for patient discomfort when administered intravenously (i.v.) using power injectors.

Purpose: To compare the frequency and intensity of patient discomfort between iodixanol and iopamidol (Isovue ${ }^{\circledR}$ ) administered i.v. using a power injector in contrast-enhanced computed tomography (CECT) of the abdomen and pelvis. Material and Methods: This was a prospective, randomized, double-blind, multicenter study of iodixanol $320 \mathrm{mg} 1 / \mathrm{mL}$ or iopamidol $370 \mathrm{mg} \mathrm{I/mL}$ on patient discomfort. The presence of discomfort (heat, pain, coldness) and intensity was verbally rated by patients on a $0-10$ scale and converted into four categories $(0$, none; $1-3$, mild; 4-7, moderate; 8-10, severe). Image quality was evaluated.

Results: Of the 299 evaluable patients enrolled at nine centers, I5I received iodixanol and I 48 received iopamidol. The average age was 58 years. lodixanol patients experienced significantly less moderate/severe discomfort ( $35.1 \%$ vs. $67.3 \%$; $P<0.000 \mathrm{I})$ or heat $(29.8 \%$ vs. $63.9 \% ; P<0.000 \mathrm{I})$, and severe discomfort $(2.6 \%$ vs. $16.3 \% ; P=0.0004)$ or heat $(2.6 \%$ vs. $15 \% ; P=0.0008)$, but three times more no discomfort $(21.2 \%$ vs. $7.5 \% ; P=0.0008)$ than iopamidol patients. Excellent image quality was in $95.4 \%$ of iodixanol vs. $89.9 \%$ of iopamidol patients $(P=0.0508)$. Overall, adverse event $(A E)$ rate excluding patient discomfort was $19.9 \%$ in the iodixanol group and $14.9 \%$ in the iopamidol group $(P=0.2870)$, but contrast-related AEs were comparable: II.3\% vs. $10.1 \%(P=0.8522)$. Delayed skin reactions occurred in $2.6 \%$ of patients in the iodixanol group and in no patient in the iopamidol group $(P=0.1226)$.

Conclusion: Patients receiving iodixanol had significantly lower moderate-to-severe or severe discomfort than patients receiving iopamidol, with heat being the major contributor. lodixanol use trended towards better image quality but the difference was not statistically significant. No significant differences in incidences of overall or contrast-related AEs or delayed skin reactions were seen between the two groups. These data support that CM osmolality may be a key determinant of patient discomfort.
\end{abstract}

\section{Keywords}

Abdomen/GI, CT, contrast agents - intravenous, Visipaque (lodixanol), Isovue (lopamidol), patient comfort

Date received: 14 October 2012; accepted: 25 August 2013

\section{Introduction}

Contrast-enhanced computed tomography (CECT) is utilized extensively in clinical diagnosis owing to its capability to cover target scan range of the body in a short time with multidetector CT scanners. It is a highly sensitive diagnostic imaging technique and is
'Nuclear Medicine, Sutter Roseville Hospital, Roseville, CA, USA

${ }^{2}$ Radiology Department, Hospital Universitario y Politécnico La Fe, Valencia, Spain

${ }^{3}$ GE Healthcare, Princeton, NJ, USA

${ }^{4}$ Ludwig-Maximilians-University Munich, Department of Clinical

Radiology, Großhadern Clinics, Munich, Germany

Corresponding author:

Frederick L Weiland, Nuclear Medicine, Sutter Roseville Hospital, One Medical Center, Roseville, CA 9566I, USA.

Email: weilanf@sutterhealth.org 
well-suited for detecting abdominal diseases. In current clinical practice, contrast media $(\mathrm{CM})$ is frequently administered intravenously (i.v.) via a power injector.

While clinicians acknowledge that CECT provides better image quality than unenhanced scans, there is concern of contrast safety to patients, including tolerability for contrast administration. Contrast-induced patient discomfort, characterized by heat sensation or pain upon injection, is a common adverse effect of iodinated CM use. Heat sensation and/or pain can lead to body movement and the quality of the images can be affected, threatening the diagnostic accuracy and subsequent clinical decisions. Managing patient comfort, especially in sensitive, apprehensive, or anxious patients, is therefore important to improve the overall tolerability, care, and patient satisfaction of any procedure.

Previous clinical studies have shown that isoosmolar contrast medium (IOCM) iodixanol is associated with less patient discomfort than low-osmolar contrast media (LOCM) (1-14). However, these studies were conducted more than 10 years ago and focused on intra-arterial injection. It is not clear how much relevance these data have to today's clinical practice, particularly to fast i.v. administration of contrast agent for CECT procedures using a power injector. Therefore, the purpose of this study was to evaluate and compare the frequency and intensity of patient discomfort following i.v. administration of iso-osmolar iodixanol or low-osmolar iopamidol in patients undergoing CECT of abdomen/pelvis as part of their routine medical care.

\section{Material and Methods}

\section{Study design and ethic}

This was a prospective, randomized, double-blind, and parallel group study to evaluate and compare contrastinduced patient discomfort and overall safety following contrast administration. The study protocol was approved by each institutional review board or ethics committee prior to the start of the study. Written informed consent was obtained from all patients prior to initiation of any study-specific procedures and the study was conducted in conformance with the Declaration of Helsinki (1996 revision), International Conference on Harmonization Guidelines for Good Clinical Practice, and any applicable local and national laws and regulations.

\section{Study population}

Patients were eligible to participate if they were at least 18 years of age and had been referred to undergo a CECT imaging of the abdomen and/or pelvis as part of their routine care. The selection of patients for a CECT scan of the abdomen/pelvis was based on consideration that it would most likely provide uniformity of contrast usage (volume and injection rate) across patients and across worldwide investigational sites for a fair comparison. Patients who had known hypersensitivities to iodine or iodinated $\mathrm{CM}$, or previous adverse reactions to iodinated $\mathrm{CM}$, as determined by the investigator, were not eligible to participate in this trial. Additionally, patients were excluded if they had received another CM within $24 \mathrm{~h}$ or if they were scheduled to receive one within the $24 \mathrm{~h}$ following iodixanol or iopamidol administration, on concomitant metformin, pregnant, undergoing dialysis, or had signs of thyrotoxicosis. Patients who had unstable clinical conditions, wherein study participation might have compromised the management of the patient, were also excluded from the study. Patients were randomly allocated in a 1:1 ratio to one of the two contrast groups. Randomization was performed locally. Each site defined its own blinding plan. Patients, investigators, and other site personnel were blinded to contrast assignment and remained blinded until the database was locked.

\section{Contrast administration}

Iodixanol $320 \mathrm{mg} \mathrm{I} / \mathrm{mL}$ (Visipaque $^{\mathrm{TM}}$, GE Healthcare, Amersham, UK) and iopamidol $370 \mathrm{mg} \mathrm{I} / \mathrm{mL}$ (Isovue ${ }^{\circledR}$, Bracco Diagnostics Inc., Princeton, NJ, USA) were provided to investigational sites by the sponsor to be used in this study. Both contrast agents were i.v. administered via a catheter or an established venous line by a power injector. The injection rate and the total volume administered were at the discretion of the prescribing physician based on patient size and/or institutional requirements for CECT procedures. Each site had the option to pre-heat or not heat the CM. If a site heated its $\mathrm{CM}$ for its first enrolled patient, the site had to continue heating $\mathrm{CM}$ for all of its enrolled patients.

\section{Study endpoints}

The primary endpoint of the study was the comparison of maximum intensity of contrast-induced patient discomfort between the two contrast agents as rated verbally by patients within $10 \mathrm{~min}$ of i.v. contrast administration. Injection site reactions were evaluated pre- and post-dose. Patient discomfort included sensations of heat, pain, or coldness as occurred at the local sites, i.e. upper trunk, lower trunk, face/head, upper extremities, lower extremities, and injection site, and/ or throughout the body (general). Maximum intensity was evaluated using the pain assessment tool described by Jensen (15) with a scale of $0-10$; this score was 
converted into four categories: 0 , none; $1-3$, mild; 4-7, moderate; $8-10$, severe. Overall patient discomfort was defined as the maximum intensity of any individual discomfort score (i.e. pain, heat, or coldness).

Secondary safety endpoints comprised the frequency of patients experiencing discomfort following contrast administration; maximum intensity and frequency of coldness, heat, and/or pain; incidence of overall adverse events (AEs) and serious AEs within $24 \mathrm{~h}$ of contrast administration via a telephone consultation; and the relationship between patient discomfort and common risk factors such as age, gender, location of injection, injection rate, contrast type and volume, use of a contrast warmer, needle/catheter size, prior history of contrast administration, peripheral vascular disease, or connective tissue disease. An AE was defined as any unfavorable and unintended medical occurrence in a subject (including an abnormal laboratory finding, sign, symptom, or disease) temporally associated with the contrast administration, irrespective to causal relationship with the contrast. Only occurrences that began or worsened in severity and/or frequency after iodixanol or iopamidol administration were recorded as AEs for the purpose of this study.

The overall image quality was assessed by on-site radiologists who were blinded to the contrast administered. Image quality was based on the presence or absence of motion artifacts, and used a three-point scale: excellent (no motion); adequate (mild motion but resulting in a diagnostic image); poor (severe motion that either significantly degraded diagnostic confidence or resulted in a recommendation to repeat the scan).

\section{Statistical analysis}

Descriptive statistics were used to summarize patient demographics and baseline characteristics, the incidence rates of patient discomfort and AEs, and image quality following each contrast administration. The study aimed to compare incidence rates of moderate and severe patient discomfort after an IV administration of different contrast agents for their CECT procedures. Chi-square tests and logistic regression analysis were employed to analyze the differences of patient discomfort between the two contrast groups and risk factors affecting the patient discomfort. The statistical significance for all tests was at a level of 0.05.

Additionally, an interim analysis was performed during the study by an Independent Data Monitoring Committee (IDMC) after the first 150 patients were enrolled to validate the initial assumptions on sample size estimation. Based on results of the interim analysis, the IDMC recommended that the study enrollment could be stopped; however, the IDMC supported continued enrollment to reach full study sample size for further evaluation of the secondary endpoints. Consequently, a total of 304 patients were enrolled in accordance with the planned sample size estimation.

\section{Results}

\section{Patient population}

A total of 304 patients were enrolled across nine centers in the United States and Europe from June to October 2011. The number of patients enrolled per center ranged between six and 90. Of these, 299 received contrast administration and were included in the analyses: 151 of them received iodixanol $320 \mathrm{mg} \mathrm{I} / \mathrm{mL}$ and 148 received iopamidol $370 \mathrm{mg} \mathrm{I} / \mathrm{mL}$. Five patients did not receive $\mathrm{CM}$ owing to administrative and/or technical reasons. Eight patients received the contrast opposite of their random allocation because their randomization cards were opened out of order. However, they received only one of the two contrast media, and all other protocol procedures were followed. Both efficacy and safety from these patients were analyzed according to the actual contrast they received. Patients' demographics, baseline characteristics, and risk factors for contrast administration are presented in Table 1 . No relevant differences were observed in demographic or baseline characteristics, with the exception for the mean weight of the patients $(P=0.0262)$. Patients randomized into the iopamidol group had significantly lower body weight than those in iodixanol group (74 vs. $79 \mathrm{~kg}$ ), probably due to the fact that there were more women in the iopamidol group ( $54 \%$ vs. $45 \%)$.

The information on contrast administration is presented in Table 2 . The total volume of contrast administered, injection rate, injection location, and contrast heating were generally comparable between the contrast groups.

\section{Patient discomfort}

The overall, moderate-to-severe, and severe patient discomfort, as well as discomfort by gender following each contrast administration, are summarized and compared in Table 3. Significantly more patients experienced no discomfort following IV administration of iodixanol $(21.2 \%)$ compared with the iopamidol administration $(7.5 \%)(P=0.0008)$. Significantly fewer patients had moderate-to-severe discomfort in the iodixanol group $(35.1 \%)$ compared to the iopamidol group $(67.3 \%)$ $(P<0.0001)$. Similarly, significantly fewer patients rated their discomfort as severe in the iodixanol group $(2.6 \%)$ compared to the iopamidol group $(16.3 \%)(P=0.0004)$. The mean patient discomfort score was statistically significant lower in the iodixanol 
Table I. Demographic and baseline characteristics.

\begin{tabular}{|c|c|c|c|c|}
\hline \multicolumn{2}{|l|}{ Variable } & $\begin{array}{l}\text { lodixanol } \\
320 \mathrm{mg} \mathrm{I/mL} \\
n=151\end{array}$ & $\begin{array}{l}\text { lopamidol } \\
370 \mathrm{mg} \mathrm{I/mL} \\
n=148\end{array}$ & $P$ value* \\
\hline \multicolumn{5}{|c|}{ Demographic characteristics } \\
\hline \multirow[t]{2}{*}{ Gender } & Male & $83(55.0)$ & $68(45.9)$ & \multirow[t]{2}{*}{0.1332} \\
\hline & Female & $68(45.0)$ & $80(54.1)$ & \\
\hline Age (years) & Mean (SD) & $57.8(15.2)$ & $58.5(15.0)$ & 0.7070 \\
\hline Height $(\mathrm{cm})$ & Mean (SD) & $169.9(10.2)$ & $168.3(10.4)$ & 0.1749 \\
\hline Weight (kg) & Mean (SD) & $78.8(18.7)$ & $73.9(19.1)$ & $0.0262^{\dagger}$ \\
\hline \multicolumn{5}{|c|}{ Baseline characteristics } \\
\hline \multicolumn{5}{|c|}{ Primary indication for patient's CECT exam, $n(\%)$} \\
\hline \multicolumn{2}{|c|}{ History of malignancy } & $72(47.7)$ & $70(47.3)$ & \\
\hline \multicolumn{2}{|c|}{ Abdominal pain } & $35(23.2)$ & 31 (20.9) & \\
\hline \multicolumn{2}{|c|}{ Abdominal or pelvic mass } & $6(4.0)$ & $9(6.1)$ & \\
\hline \multicolumn{2}{|c|}{ Suspected abscess } & $3(2.0)$ & I (0.7) & \\
\hline \multicolumn{2}{|c|}{ Miscellaneous } & $2(1.3)$ & $2(1.4)$ & \\
\hline \multicolumn{2}{|l|}{ Other } & $33(21.9)$ & $35(23.6)$ & \\
\hline \multicolumn{5}{|c|}{ Risk factors for contrast administration, $n(\%)$} \\
\hline \multicolumn{2}{|c|}{ Diabetes mellitus } & $16(10.6)$ & $12(8.1)$ & \\
\hline \multicolumn{2}{|c|}{ Use of non-steroidal anti-inflammatory drugs } & $12(7.9)$ & $17(1 \mathrm{l} .5)$ & \\
\hline \multicolumn{2}{|c|}{ Renal insufficiency } & $5(3.3)$ & $7(4.7)$ & \\
\hline \multicolumn{2}{|c|}{ Severe cardiovascular disease } & $3(2.0)$ & $8(5.4)$ & \\
\hline \multicolumn{2}{|c|}{ Congestive heart failure } & $2(1.3)$ & $0(0.0)$ & \\
\hline \multicolumn{2}{|c|}{ History of peripheral arterial disease } & $\mathrm{I}(0.7)$ & $4(2.7)$ & \\
\hline
\end{tabular}

*P values are from two-sided $t$ test at the significance level of 0.05 .

Statistically significant at 0.05 level.

Table 2. Information on contrast administration.

\begin{tabular}{|c|c|c|c|}
\hline Contrast parameter & lodixanol $320 \mathrm{mg} \mathrm{I} / \mathrm{mL} n=15 \mathrm{I}$ & lopamidol $370 \mathrm{mg} \mathrm{I/mL} n=148$ & $P$ value \\
\hline \multicolumn{4}{|l|}{ Total volume $(\mathrm{mL})$} \\
\hline Mean (SD) & $104.5(18.15)$ & $104.7(18.82)$ & 0.9304 \\
\hline Min, Max & 72,160 & 60,170 & \\
\hline \multicolumn{4}{|l|}{ Injection rate $(\mathrm{mL} / \mathrm{s})$} \\
\hline Mean (SD) & 3.0 & 2.8 & 0.2123 \\
\hline Min, Max & $1.0,5.0$ & I.0, 5.0 & \\
\hline \multicolumn{4}{|c|}{ Injection location, $n$ (\%) } \\
\hline Antecubital veins & $124(82.1)$ & $124(83.8)$ & 0.8009 \\
\hline Hand veins & $16(10.6)$ & $16(10.8)$ & \\
\hline Other veins & II (7.3) & $8(5.4)$ & \\
\hline \multicolumn{4}{|c|}{ Contrast heating, $n(\%)$} \\
\hline Pre-heating & $9(6.0)$ & $12(8.1)$ & 0.4675 \\
\hline No heating & $142(94.0)$ & $136(9 \mid .9)$ & \\
\hline
\end{tabular}

group (3.1) than in the iopamidol group (5.1) $(P<0.0001)$. When the maximum patient discomfort was analyzed by gender, statistically significant differences in favor of iodixanol were observed for both men
$(P<0.0001)$ and women $(P=0.0007)$. In a small number of procedures using pre-heated contrast agents, no obvious difference of patient discomfort was seen between pre-heated and non-heated 
Table 3. Summary of maximum patient discomfort.

\begin{tabular}{|c|c|c|c|}
\hline Variable category & $\begin{array}{l}\text { lodixanol } \\
320 \mathrm{mg} \mathrm{I/mL} \mathrm{n} \mathrm{( \% )}\end{array}$ & $\begin{array}{l}\text { lopamidol } \\
370 \mathrm{mg} \mathrm{I/mL} \mathrm{n} \mathrm{( \% )}\end{array}$ & $P$ value \\
\hline Overall maximum discomfort* $n$ & $|5|$ & 148 & 0.0012 \\
\hline None & $32(2 \mid .2)$ & II (7.5) & 0.0008 \\
\hline Mild & $66(43.7)$ & $37(25.2)$ & \\
\hline Moderate & $49(32.5)$ & $(75(5 \mathrm{I})$ & \\
\hline Severe & $4(2.6)$ & $24(16.3)$ & \\
\hline Missing & 0 & 1 & \\
\hline Moderate-to-severe discomfort & $53(35.1)$ & $99(67.3)$ & $<0.0001$ \\
\hline Severe discomfort & $4(2.6)$ & $24(16.3)$ & 0.0004 \\
\hline Male $n$ & 83 & 68 & $<0.0001$ \\
\hline None & $25(30.1)$ & $7(10.4)$ & \\
\hline Mild & $38(48.8)$ & $18(26.9)$ & \\
\hline Moderate & $20(24.1)$ & $37(55.2)$ & \\
\hline Severe & $0(0.0)$ & $5(7.5)$ & \\
\hline Missing & 0 & 1 & \\
\hline Female $n$ & 68 & 80 & 0.0007 \\
\hline None & $7(10.3)$ & $4(5.0)$ & \\
\hline Mild & $28(4 \mid .2)$ & $19(23.8)$ & \\
\hline Moderate & $29(42.6)$ & $38(47.5)$ & \\
\hline Severe & $4(5.9)$ & $19(23.8)$ & \\
\hline Patient discomfort score ${ }^{\dagger}, n$ & $|5|$ & 147 & \\
\hline Mean score (SD) & $3.1(2.57)$ & $5.1(3.24)$ & $<0.0001$ \\
\hline
\end{tabular}

*Patient discomfort score of 0-10 was converted into four categories: 0, none; I-3, mild; 4-7, moderate; and 8-10, severe.

†The intensity of patient discomfort score was measured using pain management scale of $0-10$ with 0 being none and 10 being most unbearable.

Table 4. Moderate-to-severe pain, heat, and cold sensations.

\begin{tabular}{|c|c|c|c|c|c|c|c|}
\hline Category & Contrast group & $N$ & $\begin{array}{l}\text { Moderate/ severe } \\
\text { discomfort } n(\%)\end{array}$ & $95 \% \mathrm{CL}$ & $\begin{array}{l}\text { Odds } \\
\text { ratio }\end{array}$ & $95 \% \mathrm{CL}$ & $P$ value \\
\hline \multirow[t]{2}{*}{ Cold } & lopamidol $370 \mathrm{mg} \mathrm{I/mL}$ & $147^{*}$ & II (7.5) & $(3.23,11.74)$ & & & \\
\hline & lodixanol $320 \mathrm{mg} \mathrm{I/mL}$ & $15 \mid$ & $5(3.3)$ & $(0.46,6.17)$ & 0.42 & $(0.144,1.252)$ & 0.1204 \\
\hline \multirow[t]{2}{*}{ Heat } & lopamidol $370 \mathrm{mg} \mathrm{I/mL}$ & $147 *$ & 94 (63.9) & $(56.18,7 I .7 I)$ & & & \\
\hline & lodixanol $320 \mathrm{mg} \mathrm{I/mL}$ & $|5|$ & $45(29.8)$ & $(22.51,37.10)$ & 0.24 & $(0.147,0.388)$ & $<0.0001$ \\
\hline \multirow[t]{2}{*}{ Pain } & lopamidol $370 \mathrm{mg} \mathrm{I/mL}$ & $147^{*}$ & $3(2.0)$ & $(0.00,4.33)$ & & & \\
\hline & lodixanol $320 \mathrm{mg} \mathrm{I/mL}$ & $|5|$ & $5(3.3)$ & $(0.46,6.17)$ & 1.65 & $(0.386,7.022)$ & 0.4999 \\
\hline
\end{tabular}

*Discomfort responses were missing for one patient in the iopamidol group.

$\mathrm{CL}$, Confidence limit.

procedures. All nine patients receiving pre-heated iodixanol and 11 out of 12 patients receiving preheated iopamidol experienced heat sensation. Analysis of location of patient discomfort showed that in patients receiving iodixanol, $20.5 \%$ of them reported entire body discomfort, compared to $37.8 \%$ for those receiving iopamidol $(P=0.0010)$.

A further analysis of heat, pain, or cold sensation separately revealed that moderate-to-severe heat sensations occurred less frequently in the iodixanol group $(29.8 \%)$ compared with the iopamidol group $(63.9 \%)(P<0.0001)$ (Table 4$)$ and severe heat sensation was seen in $15 \%$ of patients in the iopamidol group versus only $2.6 \%$ of patients in the iodixanol group $(P=0.0008)$. No statistical difference was observed for moderate or severe cold or pain sensations between the two contrast groups, probably due to small number of patients with these types of sensation in each group. 
Table 5. Overall image quality.

\begin{tabular}{|c|c|c|c|c|}
\hline Variable & Category & $\begin{array}{l}\text { lodixanol } \\
320 \mathrm{mg} \mathrm{I} / \mathrm{mL} \\
n=15 \mathrm{I} n(\%)\end{array}$ & $\begin{array}{l}\text { lopamidol } \\
370 \mathrm{mg} \mathrm{I/mL} \\
n=148 n(\%)\end{array}$ & $\begin{array}{l}\text { Total } \\
n=299 \text { n (\%) }\end{array}$ \\
\hline \multirow[t]{3}{*}{ Overall image quality } & Excellent & I $44(95.4)$ & $133(89.9)$ & $277(92.6)$ \\
\hline & Adequate & $7(4.6)$ & $14(9.5)$ & $21(7.0)$ \\
\hline & Poor & $0(0.0)$ & I $(0.7)$ & $\mathrm{I}(0.3)$ \\
\hline \multirow[t]{2}{*}{ Main effects (LR statistics for Type III analysis) } & Contrast group & \multicolumn{3}{|c|}{ Chi-square $=3.82, \mathrm{df}=\mathrm{I}, P=0.0508$} \\
\hline & Geographical region & \multicolumn{3}{|c|}{ Chi-square $=15.94, \mathrm{df}=\mathrm{I}, P<0.000 \mathrm{I}$} \\
\hline
\end{tabular}

Table 6. Summary of AEs excluding patient discomfort and those AEs with an incidence of $>1 \%$ in either contrast group.

\begin{tabular}{|c|c|c|c|}
\hline $\mathrm{AE}$ categories & $\begin{array}{l}\text { lodixanol } \\
320 \mathrm{mg} \mathrm{I/mL} \\
n=151 \mathrm{n}(\%)\end{array}$ & $\begin{array}{l}\text { lopamidol } \\
370 \mathrm{mg} \mathrm{I/mL} \\
n=148 n(\%)\end{array}$ & $P$ value \\
\hline Subjects with any $A E, n(\%)$ & $30(19.9)$ & $22(14.9)$ & 0.2870 \\
\hline Related AEs & $17(11.3)$ & $15(10.1)$ & 0.8522 \\
\hline \multicolumn{4}{|l|}{ Maximum intensity of AEs } \\
\hline Mild & $23(15.2)$ & $18(12.2)$ & 0.5027 \\
\hline Moderate & $7(4.6)$ & $4(2.7)$ & $0.54 \mid 3$ \\
\hline Severe & $0(0.0)$ & $0(0.0)$ & \\
\hline Serious AEs & $0(0.0)$ & I (0.7) & 0.4950 \\
\hline \multicolumn{4}{|l|}{ AEs by preferred term } \\
\hline Diarrhea & $3(2.0)$ & $2(1.4)$ & $>0.9999$ \\
\hline Nausea & $6(4.0)$ & $5(3.4)$ & $>0.9999$ \\
\hline Catheter site hemorrhage & $2(1.3)$ & $0(0.0)$ & 0.4984 \\
\hline Fatigue & $2(1.3)$ & $0(0.0)$ & 0.4984 \\
\hline Dysgeusia & $6(4.0)$ & $5(3.4)$ & $>0.9999$ \\
\hline Headache & $8(5.3)$ & $5(3.4)$ & 0.5727 \\
\hline Throat irritation & $2(1.3)$ & $0(0.0)$ & 0.4984 \\
\hline Pruritus & $3(2.0)$ & $0(0.0)$ & 0.2476 \\
\hline Rash & $2(1.3)$ & $0(0.0)$ & 0.4984 \\
\hline Urticaria & $2(1.3)$ & $0(0.0)$ & 0.4984 \\
\hline
\end{tabular}

\section{Image quality}

The overall image quality was graded as excellent for $95.4 \%$ of patients in the iodixanol group and $89.9 \%$ of patients in the iopamidol group; the difference trended in favor of iodixanol, but was not statistically significant $(P=0.0508)$ (Table 5). Only one image (iopamidol group) was graded as poor, in which motion artifacts degraded diagnostic confidence. No repeat scans were required for any patient owing to poor image quality.

\section{Adverse events}

Overall, $19.9 \%$ of patients in the iodixanol group and $14.9 \%$ of patients in the iopamidol group had an AE (excluding patient discomforts) during the study; the difference was not statistically significant $(P=0.2870)$ (Table 6). The incidence of contrast-related AEs was comparable between the two groups with $11.3 \%$ in iodixanol group and $10.1 \%$ in iopamidol group $(P=0.8522)$. The majority of these events were mild in severity. The most frequently occurring AEs were headache, dysgeusia, and nausea. Six patients receiving iodixanol exhibited seven skin and subcutaneous tissue disorders: three pruritus, two urticaria, and two rashes. All cutaneous events were delayed in their appearance, onset ranging from 2 to $18 \mathrm{~h}$ after $\mathrm{CM}$ administration. Three of the events were rated as mild and four as moderate in intensity; only the moderate events were treated. Two of the three mild events, itchy sensation in 
head and itchy in arms, were considered to be not related to $\mathrm{CM}$; the remaining five events in four subjects were considered related. Therefore, the delayed skin reaction rate for patients who received iodixanol administration was $2.6 \%$ as compared to no skin reaction reported by patients receiving iopamidol $(P=0.1226)$. All patients with skin reactions recovered. One serious AE occurred in the iopamidol group, but was considered to be unrelated to contrast (patient was hospitalized for an appendectomy, which was diagnosed during the study CT scan). One patient experienced contrast extravasation and two patients experienced bleeding post-dose in the iodixanol group. Of the two bleeding events, one patient had bleeding after a cannula insertion unrelated to $\mathrm{CM}$ and the second patient had mild bleeding at the injection site, also not related to $\mathrm{CM}$. In the iopamidol group, one patient developed a hematoma post-dose.

\section{Discussion}

Patient discomfort from contrast administration continues to be a common concern for patients during or immediately following injection because of potential for body movement and image degradation. But the frequency of the patient discomfort tends to be underreported, given that radiologists, nurses, and technicians do not routinely collect data specific to patient comfort, but only note that information when patients volunteer it (16). The present study provides results from a prospective, multicenter, double-blind, randomized study evaluating patient discomfort associated with IV administration of iso-osmolar iodixanol and low-osmolar iopamidol in patients undergoing CECT imaging of the abdomen and pelvis in today's contemporary medical practice setting. The study results provide relevant information to both referring physicians and imaging specialists on the frequency and severity of patient discomfort following administration of different contrast agents, which may help them inform patients and choose appropriate CM.

Sensation of heat or pain upon injection represents physiologic responses to contrast material, and increases in incidence and severity with increasing contrast osmolality and dose (17). Iodixanol is an isoosmolar, non-ionic, dimer that contains $\mathrm{Na}^{+}$and $\mathrm{Ca}^{++}$ions in its formulation that is isotonic with blood $\left(320 \mathrm{mg} \mathrm{I} / \mathrm{mL}=290 \mathrm{mOsm} / \mathrm{kg} \mathrm{H}_{2} \mathrm{O}\right.$ ). Iopamidol is a low-osmolar, non-ionic, monomer that is hyperosmolar to blood $\left(370 \mathrm{mg} \mathrm{I} / \mathrm{mL}=796 \mathrm{mOsm} / \mathrm{kg} \mathrm{H}_{2} \mathrm{O}\right)$. A hyper-osmolar agent causes fluid shifts in vascular and blood cells resulting in activation of vascular endothelium and vascular smooth muscle, deformation of cell membranes in blood, and vasodilation followed by vasoconstriction $(18,19)$. Conversely, an iso-osmolar agent will maintain a greater vascular stability in arterioles that serve the skeletal muscles and skin in the extremities. This vascular stability and the attenuated activation of nociceptors in nerves supplying the neurovascular bundles may result in less patient discomfort and pain.

Contrast viscosity, another physicochemical property, has received considerable attention for the possible role it plays in patient discomfort. At room temperature, iodixanol has a higher viscosity than iopamidol. Given the low rate of preheating in our study, and the fact that most CECT procedures were performed with room temperature contrast injection, one would have expected greater patient discomfort in the iodixanol group if viscosity had played a major contributory role. However, we saw a greater frequency and intensity of patient discomfort in the lower viscous iopamidol group in this study. This finding is consistent with reports in the literature (20-22) and does not support an association between viscocity and patient discomfort.

The relationship between iodine content and patient discomfort has also been a focus of research. A study by Murphy showed that diatrizoate, a high-osmolar agent, despite the similar iodine content, resulted in higher pain and discomfort rate than low-osmolar iohexol and ioxaglate (23). This result implied that iodine content was not responsible for patient discomfort during $\mathrm{CM}$ use, otherwise a high-osmolar agent that has comparable iodine content as a low-osmolar agent should have resulted in similar discomfort level. Consequently, it is believed that difference of osmolality between iodixanol and iopamidol is one of the main determinants of patient discomfort after intravascular injection, as opposed to iodine content or viscosity (22).

Our study evaluated the i.v. administration of iodixanol and iopamidol on patient discomfort during CECT of abdomen and pelvis with routine use of power injector for the contrast delivery. Our results showed that iopamidol resulted in significantly more patient discomfort, primarily driven by heat sensation. Our results were consistent with many previously published studies, despite the majority of them focused on administration via intra-arterial injection (1-14,20-27). Verow et al. (7) evaluated patient discomfort in a double-blind, randomized study in which 69 patients received iodixanol $270 \mathrm{mgI} / \mathrm{mL}$ and 65 patients received iopamidol $300 \mathrm{mg} \mathrm{I} / \mathrm{mL}$; statistically significant milder discomfort was experienced with iodixanol compared with iopamidol $(P=0.0001)$. Similar results from a study comparing iodixanol $270 \mathrm{mg} \mathrm{I} / \mathrm{mL}(n=1225)$ and iopromide $300 \mathrm{mg} \mathrm{I} / \mathrm{mL}(n=1227)$ were reported by Justesen et al. (8). In this double-blind, randomized study, the iodixanol group reported significantly less contrast-induced pain compared with the iopromide 
group $(P<0.001)$, as well as significantly less pain and/ or severe heat sensation $(P<0.001)$. A 2011 metaanalysis by McCullough (22) summarized the results of 22 intra-arterially administered comparative, doubleblind, randomized, patient comfort trials. Thirteen of the 22 trials assessed patient discomfort associated with CM $(n=3567)$; iodixanol was shown to have less discomfort regardless of severity over the LOCMs evaluated in the studies (1-13). In seven studies $(n=881)$, the incidence of pain based on severity demonstrated pronounced differences in favor of iodixanol $(1-5,7,14)$. The assessment of any pain associated with $\mathrm{CM}$ injections was reported in 10 trials $(n=3482)(1,2,5,7,8,14,24$ 27). The results demonstrated that IOCM was associated with less frequent and severe patient discomfort during intra-arterial administration. Based on their analyses, McCullough and Capasso attributed osmolality as a key determinant of $\mathrm{CM}$ discomfort.

Pain and discomfort may cause body movement, producing motion-related artifacts. Suboptimal images may lead to repeat examinations, exposing patients to additional $\mathrm{CM}$ injections and more radiation, and increasing the burden of cost. In our study, iodixanol administration resulted in a greater percentage of patients with excellent image quality compared with iopamidol, despite the lower iodine content, although the difference in image quality was short of statistical significance. This could be due to the fact that the present study was to evaluate the difference of patient discomfort between iodixanol and iopamidol, and was not powered to detect the difference in their image quality. Also, the method we utilized to assess image quality might be less rigorous: the three-point scale of excellent (no motion), adequate (mild motion but resulting in a diagnostic image), and poor (severe motion might either significantly degrade diagnostic confidence or result in a recommendation to re-scan). Additional well-controlled and adequately powered studies using a more discriminatory scale would be needed to appropriately evaluate the effect of patient discomfort on image quality.

The total number of patients reporting any AE excluding patient discomfort was $19.9 \%$ in the iodixanol group and $14.9 \%$ in the iopamidol group. The occurrence of AEs was generally more frequent in the iodixanol group in most categories. However, the differences were not statistically significant. Moreover, the AEs that were deemed as related to contrast administration was comparable between the two groups $(11.3 \%$ vs. $10.1 \%)$. One notable finding was that patients receiving iodixanol exhibited more delayed skin reactions than those who received iopamidol (4 [2.6\%] $v s$. $0[0.0 \%]$, respectively $P=0.1226$ ). This observation is consistent with existing evidence that suggests that late skin reactions may be more common with non-ionic dimeric iodinated contrast media $(28,29)$. The events that occurred were of either mild or moderate intensity, with only the moderate receiving treatment, and all events resolved without any sequelae.

There were limitations to our study. The act of asking questions of the patients following their CECT may have elicited an increase in patient discomfort reporting rate. However, the manner in which questioning occurred was scripted to be non-leading, and was performed consistently regardless of contrast; any variation introduced should have been minimal. Despite double-blinding and randomization, there was an imbalance in gender between the contrast groups in this study, with there being more women in the iopamidol group. Previous CM studies have reported higher incidence of adverse drug reactions in women (30). In our study, more severe discomfort was reported for patients receiving iopamidol, regardless of gender, and the differences were statistically significant. There is a cost differential between iodixanol and iopamidol, and cost considerations are an important component of healthcare delivery, but there was no cost analysis included in our study; future studies should be designed to include this component. Also, according ACR Manual on Contrast Media, delayed adverse reactions, particularly skin reactions, may occur 1 week following contrast material exposure, with the majority occurring between $3 \mathrm{~h}$ and 2 days (17), but in this patient discomfort trial, we only monitored patient safety for $24 \mathrm{~h}$ following $\mathrm{CM}$ administration. Additional events may have been reported if the period of patient monitoring had been extended. Patient movement following CM injection can be attributed to other factors besides discomfort, such as critical medical conditions or patient anxiety. We attempted to avoid these confounding factors by excluding patients from the study who had medical conditions that would compromise medical management of them during the procedure. Given we had only one patient with poor image quality, we believe we adequately controlled for these other factors. We only looked at contrast-enhanced CT in our study and did not include a non-CM control. Few studies have included such a control, and when they have, overall acute AEs occurred significantly more often in the monomeric CM group than in either the dimeric CM or control groups (29). Additionally such studies would provide additional information on AEs that can be attributed to the use of contrast, regardless of chemical structure and formulation. The CMs we selected to compare in our study had different concentrations of iodine: iodixanol was $320 \mathrm{mg} \mathrm{I} / \mathrm{mL}$ and iopamidol was $370 \mathrm{mg} \mathrm{I} / \mathrm{mL}$. These formulations were chosen because they are the most commonly used concentrations for abdominal/pelvic CECT procedures in clinical practice. Since osmolality, not iodine concentration, is thought 
to be the major contributor to contrast-induced discomfort, we did not believe the differences in iodine concentration would negatively impact our results. The CT scans were read locally, and did not use a centralized reading facility. The primary endpoint was patient discomfort, and the impact of patient discomfort on image quality was a secondary endpoint. It was believed that blinding and randomization should have kept bias and variation to a minimum.

In conclusion, in patients undergoing CECT imaging of the abdomen/pelvis using IV administration as part of their routine medical care, administration of isoosmolar iodixanol $320 \mathrm{mg} \mathrm{I} / \mathrm{mL}$ resulted in less frequent and severe patient discomfort than did low-osmolar iopamidol $370 \mathrm{mg} \mathrm{I} / \mathrm{mL}$, with heat being the major contributor. A statistically higher proportion of patients experienced no discomfort in the iodixanol group compared with the iopamidol group. The overall incidences of AEs and delayed skin reaction were slightly higher (not statistically significant) in iodixanol group, and contrast-related AEs were comparable between the two contrast groups. A greater proportion of subjects in the iodixanol group had excellent overall image quality, but the difference was not statistically significant. These data provide contemporary evidence for presentday clinical practice and support the concept that $\mathrm{CM}$ osmolality may be a key determinant of patient discomfort.

\section{Acknowledgements}

The authors would like to thank Carol Tseng, $\mathrm{PhD}$ and Martin Wang, MS, of H2O Clinical Services, for independently conducting the statistical analysis, as predefined in the Statistical Analysis Plan; funding for this support was provided by GE Healthcare. Appreciation also goes to Debra Mansfield, MT(ASCP) and Carl Torres, PhD, of GE Healthcare, for trial conduct. Writing assistance was provided by Peggy Hagerty, MS, and Stacy Simpson Logan, CMPP, of Winfield Consulting.

\section{Competing interests}

Dr Weiland, Dr Marti-Bonmati, and Professor Becker were principal investigators at their sites when participating in this clinical trial. Dr Lim is an employee of GE Healthcare and holds stock in the company.

\section{Funding}

The study was sponsored and financially supported by GE Healthcare, Princeton, NJ, manufacturer of iodixanol (Visipaque $^{\circledR}$ ).

\section{References}

1. Palmers Y, De Greef D, Grynne BH, et al. A doubleblind study comparing safety, tolerability and efficacy of iodixanol $320 \mathrm{mg} \mathrm{I} / \mathrm{ml}$ and ioxaglate $320 \mathrm{mg} \mathrm{I} / \mathrm{ml}$ in cerebral arteriography. Eur J Radiol 1993;17:203-209.

2. Poirier VC, Monsein LH, Newberry PD, et al. Doubleblind, randomized comparison of iodixanol 320 and iohexol 300 for cerebral angiography. Invest Radiol 1994;29(Suppl. 2):S43-S44.

3. Singh K, Sundgren R, Bolstad B, et al. Iodixanol in abdominal digital subtraction angiography. A randomized, double-blind, parallel trial with iodixanol and iohexol. Acta Radiol 1993;34:242-245.

4. Tveit K, Bolz KD, Bolstad B, et al. Iodixanol in cardioangiography. A double-blind parallel comparison between iodixanol $320 \mathrm{mg} \mathrm{I} / \mathrm{ml}$ and ioxaglate $320 \mathrm{mg} \mathrm{I} / \mathrm{ml}$. Acta Radiol 1994;35:614-618.

5. Pugh ND, Sissons GR, Ruttley MS, et al. Iodixanol in femoral arteriography (phase III): a comparative doubleblind parallel trial between iodixanol and iopromide. Clin Radiol 1993;47:96-99.

6. Klow NE, Levorstad K, Berg KJ, et al. Iodixanol in cardioangiography in patients with coronary artery disease. Tolerability, cardiac and renal effects. Acta Radiol 1993;34:72-77.

7. Verow P, Nossen JO, Sheppick A, et al. A comparison of iodixanol with iopamidol in aorto-femoral angiography. Br J Radiol 1995;68:973-978.

8. Justesen P, Downes M, Grynne BH, et al. Injection-associated pain in femoral arteriography: a European multicenter study comparing safety, tolerability, and efficacy of iodixanol and iopromide. Cardiovasc Intervent Radiol 1997;20:251-256.

9. Andersen PE, Bolstad B, Berg KJ, et al. Iodixanol and ioxaglate in cardioangiography: a double-blind randomized phase III study. Clin Radiol 1993;48:268-272.

10. Fischbach R, Landwehr P, Svaland M, et al. Spiral CT angiography of the abdominal aorta. Comparison of iodixanol and ioversol. Invest Radiol 1999;34:374-380.

11. Flinck A, Selin K. Vectorcardiographic changes during cardioangiography with iodixanol and ioxaglate. Int $\mathbf{J}$ Cardiol 2000;76:173-180.

12. Hekster RE, Morre HH, Cleyndert $\mathrm{P}$, et al. Intra-arterial digital subtraction angiography with isotonic dimeric (iodixanol) and monomeric (iohexol) nonionic contrast media: radiographic, clinical and neurophysiological evaluation. Neuroradiology 1995;37:48-50.

13. Hill JA, Cohen MB, Kou WH, et al. Iodixanol, a new isosmotic nonionic contrast agent compared with iohexol in cardiac angiography. Am J Cardiol 1994;74:57-63.

14. Manke C, Marcus C, Page A, et al. Pain in femoral arteriography. A double-blind, randomized, clinical study comparing safety and efficacy of the iso-osmolar iodixanol $270 \mathrm{mg} \mathrm{I} / \mathrm{ml}$ and the low-osmolar iomeprol $300 \mathrm{mg} \mathrm{I} / \mathrm{ml}$ in 9 European centers. Acta Radiol 2003;44:590-596.

15. Jensen MP. Chapter 5: Pain assessment in clinical trials and Appendix 5.1: Pain quality assessment scale (PQAS). In: Wittink HM, Carr DB (eds). Pain Research and Clinical Management. Pain Management: Evidence, Outcomes and Quality of Life, A Sourcebook. London: Elsevier, 2008. 
16. Amaral JG, Traubici J, BenDavid G, et al. Safety of power injector use in children as measured by incidence of extravasation. Am J Roentgenol 2006;187:580-583.

17. ACR Committee on Drug and Contrast Media. Chapter 4: Allergic-like and physiologic reactions to intravascular iodinated contrast media. In: ACR Manual on Contrast Media. Volume 9. Reston, VA: ACR, 2013, pp.21-27.

18. Jung F, Mrowietz C, Rickert D, et al. The effect of radiographic contrast media on the morphology of human erythrocytes. Clin Hemorheol Microcirc 2008;38:1-11.

19. Fernandez-Rodriguez S, Edwards DH, Newton B, et al. Attenuated store-operated $\mathrm{Ca} 2+$ entry underpins the dual inhibition of nitric oxide and EDHF-type relaxations by iodinated contrast media. Cardiovasc Res 2009;84:470-478.

20. Davidson C, Stacul F, McCullough PA, et al. Contrast medium use. Am J Cardiol 2006;98:42K-58K.

21. Haussler MD. Safety and patient comfort with iodixanol: a postmarketing surveillance study in 9515 patients undergoing diagnostic CT examinations. Acta Radiol 2010;51:924-933.

22. McCullough PA, Capasso P. Patient discomfort associated with the use of intra-arterial iodinated contrast media: a meta-analysis of comparative randomized controlled trials. BMC Med Imaging 2011;11:12.

23. Murphy G, Campbell DR, Fraser DB. Pain in peripheral arteriography: An assessment of conventional versus ionic and non-ionic low-osmolality contrast agents. J Can Assoc Radiol 1988;39:103-106.
24. Thorstensen O, Albrechtsson U, Calissendorff B, et al. Iodixanol in femoral arteriography. A randomized, double-blind, phase III, parallel study with iodixanol $270 \mathrm{mg} \mathrm{I} / \mathrm{ml}$ and iohexol $300 \mathrm{mg} \mathrm{I} / \mathrm{ml}$. Acta Radiol 1994;35:629-631.

25. Rosenblum JD, Siegel EL, Leef J, et al. Iodixanol and ioxaglate in adult aortography and peripheral arteriography: a phase III clinical trial. Acad Radiol 1996;3(Suppl. 3):S514-S518.

26. Siegel EL, Rosenblum JD, Eckard DA, et al. Comparison of iodixanol and ioxaglate for adult aortography and renal/visceral angiography: a phase III clinical trial. Acad Radiol 1996;3(Suppl. 3):S507-S513.

27. Manninen HI, Yang XM, Soder H, et al. Comparison of iodixanol 270 with iohexol 300 in infrapopliteal arteriography. Digital densitometric analysis of angiographic opacification. Acta Radiol 1999;40:291-295.

28. Webb JA, Stacul F, Thomsen HS, et al. Late adverse reactions to intravascular iodinated contrast media. Eur Radiol 2003;13:181-184.

29. Schild HH, Kuhl CK, Hubner-Steiner U, et al. Adverse events after unenhanced and monomeric and dimeric contrast-enhanced CT: a prospective randomized controlled trial. Radiology 2006;240:56-64.

30. Kopp AF, Mortele KJ, Cho YD, et al. Prevalence of acute reactions to iopromide: postmarketing surveillance study of 74,717 patients. Acta Radiol 2008;49:902-911. 